\title{
Impacto do rompimento da barragem em Mariana- MG na saúde da população ribeirinha da cidade de Colatina-ES.
}

\section{The impact of disruption of the barrage in Mariana- MG on the health of the riverside population in the city of Colatina-ES.}

El impacto de la interrupción de la barrera en MarianaMG en la salud de la población ribereña en la ciudad de Colatina-ES.

\author{
Ederson Mieis Rocha ${ }^{1}, 2$ \\ Lucas Grobério Moulim de Moraes $^{2}$ \\ Larissa Valério de Almeida ${ }^{2}$ \\ Letícia Rego Dalvi \\ Luciano Castiglioni Andriato ${ }^{2}$ \\ Lucas Kefler Bergamaschi \\ Luiza Seidel Dala Bernardina ${ }^{2}$ \\ Willian Borges Pereira ${ }^{2}$ \\ Vanilda Gomes Gimenez ${ }^{3}$ \\ Orlando Chiarelli Neto ${ }^{4}$ \\ Herivelto dos Santos Almeida ${ }^{5}$
}

\begin{abstract}
RESUMO: A água é um direito do ser humano, que além de ser fornecida em quantidade adequada, deve ser qualitativamente favorável ao consumo. Objetivou-se neste estudo mensurar os impactos na população ribeirinha da cidade Colatina-ES provocados pelo desprendimento de rejeitos de mineração no Rio Doce, provenientes da cidade de Mariana-MG. Os métodos utilizados para o projeto foram embasados em uma pesquisa teórica seguida de um trabalho em campo de

1 Fisioterapeuta pela Universidade Vila Velha.

2 Acadêmico de Medicina do Centro Universitário do Espírito Santo - UNESC Colatina

3 Mestre em Terapia Intensiva pelo Instituto Brasileiro de Terapia Intensiva. Graduação em Enfermagem pelo Centro Universitário do Espírito Santo - UNESC Colatina

4 Doutor em Bioquímica pela Universidade de São Paulo - USP

5 Professor de Bioestatística no Centro Universitário do Espírito Santo - UNESC Colatina

Autor correspondente: Lucas Grobério Moulim de Moraes - Avenida Treze de Maio, № 662, Centro / Pancas, Espírito Santo, Brasil. CEP 29.750-000 - e-mail: lucasgromoulimdm@hotmail.com
\end{abstract}


caráter longitudinal, quantitativo e não probabilístico. A abordagem, no âmbito epidemiológico, demonstrou aumento expressivo na incidência de sinais e sintomas prodrômicos de patologias, como a diarreia, febre e afecções de pele e fâneros que obtiveram evolução aproximada de 172,7\%, $133,3 \%$ e 35,3\%, respectivamente. Tais parâmetros estão intimamente associadas as consequências do desastre ambiental, pelas alterações do meio ambiente, interrupção do fornecimento de água, contaminação hídrica, dentre outras. Notou-se necessidade de redefinir temáticas de educação em saúde pelas instituições governamentais para o manejo de qualidade da água. Sintomas como febre, diarreia, e alterações de pele tiveram elevação das taxas associadas com efeitos adversos no âmbito biológico, psicológico, social e econômico.

Palavras-chave: Água; Rejeitos de minério; Rio Doce; População ribeirinha; Saúde Pública.

\begin{abstract}
Water is a human right which should be provided in adequate quantity and quality favorable to consumption. The aim of this study is to measure the impacts on the riverside population of the city of Colatina-ES caused by the spread of iron mining debris and waste in the Rio Doce coming from a dam break located in the town of Mariana-MG. The methods used in this study used together theoretical research and fieldwork using a longitudinal aspect, quantitative and nonprobabilistic. The approach in the epidemiological level showed significant increase in the incidence of prodromal signs and symptoms of diseases such as diarrhea, fever and skin and appendages disorders that obtained approximate increase of $172.7 \%, 133.3 \%$ and $35.3 \%$ respectively. Such parameters are associated with the consequences of environmental disaster resulting in impacts on the environment, interruption of water supply, the water contamination and anothers. It was noted the need to redefine the themes in education in coming health by governmental institutions and public agencies government to management of the water quality. Symptoms seen as fever, diarrhea and skin diseases have emerging rates associated with the adverse effects on biological boundaries, psychological, social and economic aspects.
\end{abstract}

Keywords: Water; Ore waste; Rio Doce; Riverine population; Public health.

RESUMEN: El agua es un derecho humano, que además de ser proporcionado en cantidad adecuada, debe ser cualitativamente favorable para el consumo. El objetivo de este estudio para medir el impacto en la población local de la ciudad de Colatina-ES causada por el desprendimiento de residuos mineros en el Rio Doce, de la ciudad de Mariana, Minas Gerais. Los métodos utilizados para el proyecto se basa en un trabajo de investigación teórica seguida de un campo de carácter longitudinal, cuantitativay no probabilístico. El enfoque, el nivel epidemiológico, mostró un aumento significativo en la incidencia de signos y síntomas de enfermedades como la diarrea, enfermedades de la fiebre y de la piel y faneros que obtuvieron incremento aproximado de 172,7\%, 133,3\% y $35,3 \%$ prodrómicos respectivamente. Estos parámetros están estrechamente relacionados con las consecuencias de un desastre ambiental, por los cambios en el medio ambiente, la interrupción del suministro de agua, la contaminación del agua, entre otros. Se señaló la necesidad de redefinir los temas de educación para la salud por las instituciones gubernamentales para la gestión de la calidad del agua. Los síntomas tales como fiebre, diarrea y cambios en la piel habían elevado las 


\section{$33 / /$}

tasas asociadas con efectos adversos en contexto biológico, psicológico, social y económica. Palabras clave: agua; Relaves de hierro; Rio Doce; Población local; Salud pública.

\section{INTRODUÇÃO}

No Brasil, existem cerca de 1.400 empresas de mineração que extraem principalmente metais, dentre eles o manganês, o ouro, o amianto, o cobre, o ferro e o zinco. As águas das rochas mineralizadas contêm alta concentração de metais pesados, utilizados no processo de depuração. Os quais podem causar contaminação em áreas com diversos níveis de vulnerabilidade, potencializada pelas ações humanas ${ }^{1,2}$.

O grau de vulnerabilidade da área geográfica ou da comunidade afetada é um dos fatores que intensificam suas consequências. Tanto a magnitude dos eventos, como suas consequências socioeconômicas, ambientais e sanitárias levam danos à saúde das populações ${ }^{3}$.

As catástrofes comprometem o comportamento psicológico das comunidades e alteram a rotina de vida, o que desencadeia agravos patológicos decorrentes do "pós-calamidade", como Depressão, Síndrome do Pânico, Burnout, Hipertensão arterial, Diabetes, Urticárias, Gastrites, e Doenças Cerebrovasculares. Dentro deste contexto, pode-se relevar também, o aumento de sinais prodrômicos associados ao consumo e contato com a água, como a diarreia, febre e alterações da pele. Isso porque, a água, é um substrato fundamental para diversas reações metabólicas. Essa substância atua em processos fisiológicos como a absorção, digestão, excreção, transporte de nutrientes e gases no sistema circulatório, a manutenção da temperatura e o controle do fluxo de outras substâncias para o meio intracelular e extracelular. Qualquer alteração na composição da água ingerida pode ocasionar desvios na homeostase corporal $1^{4}$.

A Agência Nacional de Águas - ANA $(2015)^{5}$ estabelece o uso de índices físico-químicos que informam a população e direcionam o planejamento para a utilização de recursos hídricos de qualidade. Os principais parâmetros de qualidade que as Unidades da Federação utilizam são: Índice de qualidade das Águas (IQA), Índice de Contaminação por Tóxicos, Índice de Balneabilidade (IB), Índice de Estado Trófico (IET), Índice de Qualidade de Água para a Proteção da Vida Aquática (IVA) e Índice de Qualidade da Água Bruta para fins de Estabelecimento Público (IAP).

Dentre os parâmetros físicos e químicos, avalia-se a cor, odor, sabor, sais e concentração de oxigênio dissolvido na água. A quantidade de matéria orgânica reflete na concentração de oxigênio, proliferação dos seres vivos, que na presença de metais pesados podem ocasionar processos de bioacumulação ${ }^{6,7}$.

Para o consumo humano, faz-se necessário alguns cuidados de manejo com a água. De acordo com o Comitê da Bacia Hidrográfica do Rio Doce, CHB-DOCE (2015)를 as águas armazenadas em áreas externas necessitam de recipientes com tampa, não havendo nenhuma fresta, para 
evitar a deposição de ovos, principalmente de mosquitos Aedes aegypti. Para maior eficiência, a utilização de uma tela entre o recipiente e a tampa é um método viável. Caixas d'águas devem ficar completamente vedadas para impedir a entrada de animais e a consequente disseminação de moléstias.

O uso de água de poços rasos, minas e bicas não é recomendado para o consumo humano, pois está sujeito à contaminação por agentes microbiológicos, matéria orgânica proveniente de esgoto não tratado e poluentes químicos ${ }^{8}$.

Aágua para consumo humano deve ser potável e proveniente de fontes seguras de abastecimento9. Em locais onde não há acesso à água tratada, recomenda-se realizar o tratamento doméstico pontual com o consumo restrito desta no mesmo dia, para evitar contaminação e enfermidades.

No entanto, a ingestão de água tratada, ainda que no mesmo dia, pode ocasionar sinais e sintomas de alergias inicialmente, e a longo prazo, as neoplasias, quando houver presença de metais pesados. $\mathrm{O}$ chumbo $(\mathrm{Pb})$, além do grande potencial cancerígeno, também pode expressar afecções nos sistemas cardiovascular, renal, imunológico, nervoso e reprodutivo. $\mathrm{O}$ acúmulo de mercúrio $(\mathrm{Hg})$ no organismo designa-se principalmente no cérebro e rins, podendo debilitar funções cerebrais incorrendo em, por exemplo, Alzheimer. $\mathrm{O}$ cádmio (Cd) é um agente causador de inflamação pulmonar e hepatopatias, com acúmulos em túbulos renais proximais, causando distúrbios urinários como a excreção aumentada de cálcio. $\mathrm{O}$ cobre $(\mathrm{Cu})$ potencializa o metabolismo oxidativo. $\mathrm{O}$ zinco ( $\mathrm{Zn})$ em altas concentrações surte efeito tóxico com alterações enzimáticas. Por fim, o cromo (Cr) é um carcinógeno predispondo tumores pulmonares e irritação de pele ${ }^{10}$.

A exposição à lama contaminada com metais pesados pode desencadear reações alérgicas na pele, como irritações, vermelhidão, inchaços, pequenas bolhas, sensação de queimação e desconforto, "principalmente nas áreas de dobras da pele, que ficam mais úmidas, como articulações e genitálias" ${ }^{11}$. Por isso, faz-se necessário investigações no âmbito epidemiológico.

No dia cinco de novembro de 2015, ocorreu, na cidade de Mariana (estado de Minas Gerais, Brasil), o rompimento de uma barragem contendo resíduos provenientes da extração de minério de ferro, atingindo toda a bacia hidrográfica do Rio Doce e as cidades pertencentes a essa bacia, dentre elas, a cidade de Colatina, localizada na região noroeste do estado do Espírito Santo.

Segundo o Instituto Brasileiro de Meio Ambiente e dos Recursos Renováveis - IBAMA (2015) ${ }^{12}$, o rompimento da barragem de Fundão, em Bento Rodrigues, distrito de Mariana-MG, apresentava rejeitos e dejetos de mineração, foi elencado como o maior desastre ambiental da história do Brasil, e com consequências inenarráveis para populações dependentes do Manancial onde esses dejetos se depositaram: o Vale do rio Doce.

No dia seis de dezembro de 2015, o Serviço Autônomo de Água e Esgoto (SAAE) de Baixo Guandu-ES, mostrou a presença de arsênio (2,6394 mg/L), chumbo (1,03 mg/L), alumínio (1.405,5 
$\mathrm{mg} / \mathrm{L})$, ferro $(2,784 \mathrm{mg} / \mathrm{L})$, manganês $(61,222 \mathrm{mg} / \mathrm{L})$ e bário $(5,385 \mathrm{mg} / \mathrm{L})$, entre outros elementos, em níveis muito acima do recomendável, que contaminou toda extensão do Rio Doce, desde a cidade de Mariana - MG até a costa do Espírito Santo ${ }^{13}$. Entretanto, estes dados foram veiculados por meio não-científico, e faz-se necessárias maiores investigações técnicas.

A chegada da "lama" de rejeito na cidade proporcionou, primeiramente, um grande impacto no âmbito psicossocial por atingir o rio tido como símbolo da cidade. Outra repercussão a ser ressaltada é o armazenamento de água feito pela população durante os dias de suspensão do fornecimento hídrico, sem que houvesse orientações adequadas sobre a estocagem, propiciando a colonização de agentes e desenvolvimento de vetores, resultando em agravos à saúde. Por isso, a importância na investigação dos impactos ao bem-estar da sociedade, visando a origem e manejo da água de consumo, assim como avaliar os possíveis danos à integridade física e psíquica-comportamental ante aos desafios adaptativos desencadeados pelo desastre ambiental.

\section{MÉTODOS}

Os dados deste artigo foram obtidos por acadêmicos do curso de Medicina do Centro Universitário do Espírito Santo-UNESC. Utilizou-se um estudo de caráter longitudinal, abordando métodos de pesquisa de caráter quantitativo e não probabilístico por meio de pesquisa de campo a partir de questionários sistemáticos na população ribeirinha da cidade de Colatina-ES no período prévio ao impacto do rompimento da barragem em Mariana-MG e posteriormente à chegada da água acometida. Visou no total aplicar três questionários: dia 0 (dia que antecede a passagem dos rejeitos), 60 e 120 dias após o evento. (Ver Apêndices A e B).

O primeiro questionário (dia zero), foi aplicado no dia 9 de Novembro de 2015, data que precede a chegada dos rejeitos da produção de minério. Na segunda e terceira visita foram realizadas orientações (quanto ao manejo da água e prevenção de doenças) e aplicação dos questionários, que ocorreram no terceiro e quinto mês, respectivamente, após a passagem dos rejeitos da mineradora. Portanto, foram realizadas três abordagens, em momentos distintos, sendo mantidos os mesmos entrevistados da primeira. Assim, é possível sistematizar um comparativo, nesta população, visando o antes e o depois da chegada da Lama à Colatina - ES.

Para a conciliação de resultados, foi utilizado o Teste Qui-quadrado, o qual segundo Vieira $(2008)^{14}$ consiste em fazer uma inferência na qual duas hipóteses contraditórias realizadas, são baseadas em conhecimentos de parte dos fatos. A primeira hipótese é chamada de $\mathrm{H}_{0}$ (hipótese de nulidade), que na maioria das vezes diz que não há diferenças entre os grupos de dados. A outra hipótese é chamada de $\mathrm{H}_{1}$ (hipótese alternativa) é a que contradiz a anterior. O teste não elimina a probabilidade de erro, mas fornece o p-valor (valor de probabilidade). Por convenção, se o p-valor for menor do que 0,05 ( $\mathrm{p}<0,05)$, conclui-se que a hipótese de nulidade deve ser rejeitada. Se o valor-p for maior que 0,05 ( $p>0,05)$, os pesquisadores não rejeitam o H0, pois os resultados encontrados são considerados estatisticamente insignificantes. Além deste, utilizou-se o teste qui- 
quadrado de aderência ou teste $\mathrm{G}$ de homogeneidade, que, segundo Callegari-Jacques (2008) ${ }^{15}$, tem por finalidade verificar se uma distribuição observada de frequências pactua com uma distribuição esperada (determinada em teoria).

Todo o processo desta pesquisa foi submetido e aprovado pelo Comitê de Ética em Pesquisa do Centro Universitário do Espírito Santo (CEP-UNESC), CAAE: 53467216.8.0000.5062.

\section{RESULTADOS}

Partindo de uma amostragem inicial de 116 entrevistados, da primeira abordagem em campo de pesquisa, o estudo contou com uma variedade extensa de perfis de pessoas. A visão geral desta população pode ser analisada na Tabela 1 .

Tabela 1- Perfil da população pesquisada

\begin{tabular}{|c|c|c|c|c|}
\hline Variáveis & Opções & $\mathrm{N}=116$ & & $\%$ \\
\hline \multirow{3}{*}{ Número de moradores na casa } & 1 & 9 & & \multirow{3}{*}{7.76} \\
\hline & 2 a 4 & 77 & 66.38 & \\
\hline & $>4$ & 30 & 25.86 & \\
\hline \multirow{4}{*}{ Idade (Anos) } & 12 a 25 & 16 & & \multirow[t]{4}{*}{13.79} \\
\hline & 26 a 60 & 66 & 56.90 & \\
\hline & $>60$ & 33 & 28.45 & \\
\hline & Não respondeu & 1 & 0.86 & \\
\hline \multirow{3}{*}{ Crianças na casa } & $\operatorname{Sim}$ & 42 & & \multirow[t]{3}{*}{36.21} \\
\hline & Não & 73 & 62.93 & \\
\hline & Não respondeu & 1 & 0.86 & \\
\hline \multirow{2}{*}{ Idosos na casa } & Sim & 47 & & \multirow[t]{2}{*}{40.52} \\
\hline & Não & 69 & 59.48 & \\
\hline \multirow{5}{*}{ Escolaridade } & Analfabeto & 18 & & \multirow[t]{5}{*}{15.52} \\
\hline & Fundamental & 53 & 45.69 & \\
\hline & Médio & 33 & 28.45 & \\
\hline & Superior & 11 & 9.48 & \\
\hline & Não respondeu & 1 & 0.86 & \\
\hline \multirow{3}{*}{$\begin{array}{c}\text { Moradores com necessidades } \\
\text { especiais }\end{array}$} & Sim & 17 & & \multirow[t]{3}{*}{14.66} \\
\hline & Não & 96 & 82.76 & \\
\hline & Não respondeu & 3 & & \\
\hline \multirow{4}{*}{ Tempo de moradia } & $<1$ ano & 14 & & \multirow[t]{4}{*}{12.07} \\
\hline & 1 - 5 Anos & 21 & 18.10 & \\
\hline & $>5$ anos & 75 & 64.66 & \\
\hline & Não respondeu & 6 & 5.17 & \\
\hline \multirow{4}{*}{ Tipo de construção } & Alvenaria & 107 & & \multirow[t]{4}{*}{92.24} \\
\hline & Madeira & 2 & 1.72 & \\
\hline & Barro & 2 & 1.72 & \\
\hline & Outro & 2 & 1.72 & \\
\hline
\end{tabular}


Continuação

\begin{tabular}{lcccc} 
& Não respondeu & 3 & 2.59 & \\
\hline \multirow{3}{*}{ Destino sanitário } & Rede esgoto & 49 & & 42.24 \\
& Rio & 57 & 49.14 & \\
& Fossa & 8 & 6.90 \\
\hline
\end{tabular}

Tabela 2 - Módulos de abordagens específicos

\begin{tabular}{|c|c|c|c|c|}
\hline Variável & Questionário & Opções & $\mathbf{N}$ & $\%$ \\
\hline \multirow{5}{*}{$\begin{array}{l}\text { Confiança da população em informações } \\
\text { fornecidas por órgãos específicos de qualidade de } \\
\text { beneficiamento sobre a água para consumo }\end{array}$} & \multirow{3}{*}{$\mathrm{Q}^{2}$} & Confia & 15 & 15,3 \\
\hline & & Não confia & 83 & 84,7 \\
\hline & & Não respondeu & 1 & - \\
\hline & \multirow{2}{*}{$\mathrm{Q}^{3}$} & Confia & 11 & 11,22 \\
\hline & & Não confia & 87 & 88,78 \\
\hline \multirow{9}{*}{$\begin{array}{l}\text { Grau de dificuldade encontrada no manejo da } \\
\text { água pela população na situação apresentada }\end{array}$} & \multirow{5}{*}{$\mathrm{Q}^{2}$} & Nada & 15 & 15,3 \\
\hline & & Pouco & 23 & 23,5 \\
\hline & & Muito & 43 & 43,9 \\
\hline & & Totalmente & 17 & 17,3 \\
\hline & & Não respondeu & 1 & - \\
\hline & \multirow{4}{*}{$\mathrm{Q}^{3}$} & Nada & 9 & 9,2 \\
\hline & & Pouco & 22 & 22,4 \\
\hline & & Muito & 44 & 44,9 \\
\hline & & Totalmente & 23 & 23,5 \\
\hline \multirow{6}{*}{$\begin{array}{c}\text { Utilização da água coletada diretamente do Rio } \\
\text { Doce }\end{array}$} & \multirow{3}{*}{$\mathrm{Q} 1^{1}$} & Sim & 16 & 14,16 \\
\hline & & Não & 97 & 85,84 \\
\hline & & Não respondeu & 3 & - \\
\hline & \multirow{2}{*}{$\mathrm{Q}^{2}$} & Sim & 10 & 10,1 \\
\hline & & Não & 89 & 89,9 \\
\hline & \multirow[t]{2}{*}{$\mathrm{Q}^{3}$} & $\begin{array}{l}\text { Sim } \\
\text { Não }\end{array}$ & $\begin{array}{l}14 \\
84 \\
\end{array}$ & $\begin{array}{l}14,29 \\
85,71 \\
\end{array}$ \\
\hline \multirow{7}{*}{$\begin{array}{l}\text { Conhecimento dos entrevistados quanto ao } \\
\text { manejo adequado da água não potável }\end{array}$} & & Sim & 30 & 26,32 \\
\hline & \multirow[t]{2}{*}{$\mathrm{Q} 1^{1}$} & Não & 84 & 73,68 \\
\hline & & Não respondeu & 2 & - \\
\hline & \multirow{3}{*}{$\mathrm{Q}^{2}$} & Sim & 55 & 57,29 \\
\hline & & Não & 41 & 42,71 \\
\hline & & Não respondeu & 3 & - \\
\hline & $\mathrm{Q}^{3}$ & $\operatorname{Sim}_{\text {Não }}$ & $\begin{array}{l}45 \\
53 \\
\end{array}$ & $\begin{array}{l}45,92 \\
54,08\end{array}$ \\
\hline
\end{tabular}

( $\left.{ }^{1}\right)$ Q1: Aplicação do primeiro questionário (novembro/2015), N=116. (²) Q2: Aplicação do segundo questionário (janeiro/2016), N=99; $\left(^{3}\right)$ Q3: Aplicação do terceiro questionário (março/2016), N=98;

O perfil de escolaridade da população estudada expõe que 45,69\% dos 115 entrevistados, que responderam ao questionamento específico, chegaram ao ensino fundamental, 28,45\% atingiram o ensino médio e somente $9,48 \%$ concluíram curso superior. Registra-se, ainda, que 15,52\% sequer foram alfabetizados. Evidencia-se, com isso, uma nítida relação entre o reduzido grau de escolaridade e a elevada fração de participantes que desconheciam a temática da potabilidade da água no início do trabalho, o que demonstra um aprendizado deficitário diante da complexidade do tema abordado. 
Um dos objetivos do presente trabalho é a educação em saúde, pela qual se buscou analisar o conhecimento prévio da população a respeito de métodos para tornar potável a água não potável oriunda das torneiras e de coleções hídricas (de reserva), bem como esclarecer sobre o manejo correto. No primeiro questionário, verificou-se que $73,68 \%$ dos entrevistados tiveram um desempenho negativo quanto ao nível de conhecimento do assunto em questão. Já no segundo questionário, observou-se um aumento do nível informacional dos entrevistados ao patamar de $57,29 \%$ ( $n=96)$, o qual foi atribuído às orientações fornecidas pelos pesquisadores à população. Por fim, no terceiro e último questionário notou-se que 54,08\% dos 98 entrevistados negaram ter conhecimento das técnicas de potabilidade da água. (Ver Tabela 2).

O estudo expõe resultados relevantes acerca da confiabilidade dos cidadãos nas informações prestadas por órgãos, instituições e empresas responsáveis pelo controle de qualidade da água. A evolução desta categoria mostrou que na segunda (Q2) e terceira (Q3) aplicações da pesquisa: Q2, 83 de 98 pesquisados desconfiam das informações sobre a qualidade da água atestada por órgãos governamentais; no Q3, esse número sobe para 87 pessoas.

Quando interrogados, no primeiro questionário, sobre a utilização de água coletada diretamente do Rio Doce, 14,16\% dos entrevistados responderam "Sim" e 85,84\%, "Não". No segundo questionário, 10,10\% responderam "Sim", e, 89,90\%, "Não". No terceiro questionário 14,29\% responderam "Sim", 85,71\%, "Não". Os valores totais de entrevistados nos questionários 1, 2 e 3 foram respectivamente 115,99 e 98 .

O grau de dificuldade encontrado pela população para lidar com os desafios e adaptações consequentes da qualidade da água disponível (atividades diárias domésticas, lazer, alimentação, etc.), correlacionando períodos dos meses de janeiro e março de 2016. Assim, podemos afirmar que das 98 pessoas que responderam à pergunta, no mês de janeiro, 15,3\% disseram "Nada", 23,5\% "Pouco", 43,9\% "Muito" e 17,3\% "Totalmente". Já no mês de março, observam-se alterações expressivas referentes às respostas "Totalmente": 23,5\% e "Nada" 9,2\%, "Muito" e "Pouco" somaram $63,7 \%$.

Para avaliação da saúde, foram elencadas três categorias prodrômicas: febre, diarreia e afecções de pele e fâneros. As incidências desses itens ao longo da pesquisa foram dispostas na Figura 1. Dessa forma, evidencia-se um aumento no número de pessoas com tais sintomas, sendo que os casos de febre cresceram cerca de 133,33\% na comparação dos meses de novembro de 2015 a março de 2016, bem como os de diarreia que se elevaram em 172,72\% no mesmo período. Afecções de pele e fâneros cresceram cerca de $35,3 \%$ em comparação com os meses de janeiro e março de 2016. 


\section{Figura 1 - Incidências de sinais e sintomas ao longo do tempo}

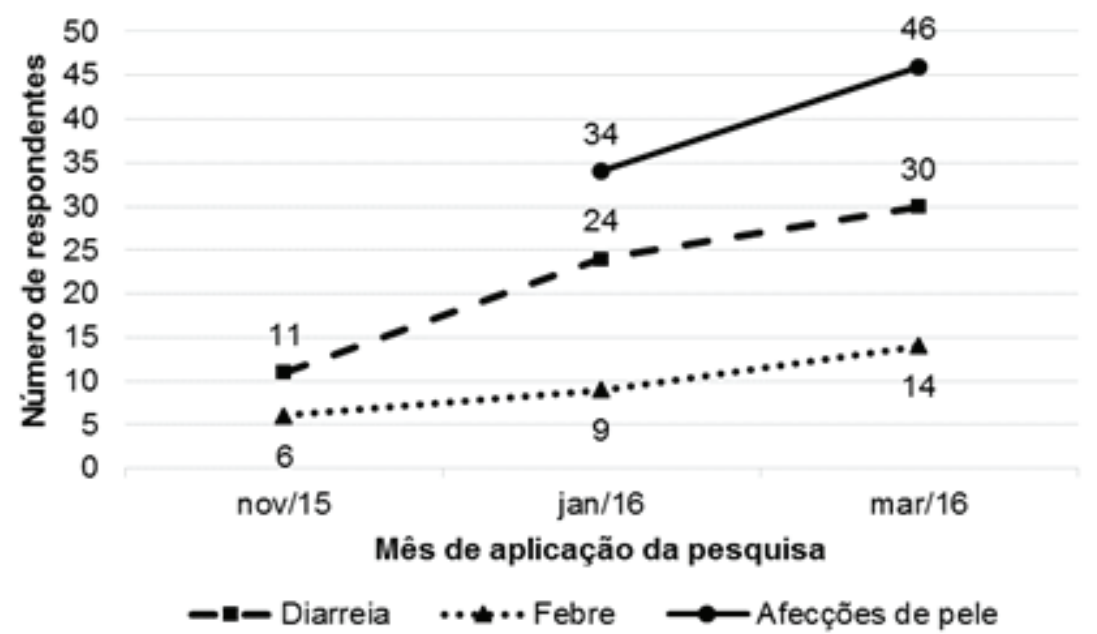

É importante salientar, que mesmo com a redução da população de pesquisa ao longo da aplicação dos questionários, os parâmetros avaliados permanecem em ascendência numérica.

Seguindo a vertente dos sintomas, verificou-se que a diarreia teve maior incidência em alguns bairros, fazendo assim uma correlação de incidência referente a uma certa região. Contudo, sobre execução dos Testes Qui-quadrado e $G$, não foi possível definir como padrão de pesquisa populacional os resultados obtidos, visto que o valor $\mathrm{p}$ correspondeu a um valor maior de 5\% $(0,05)$ em todas as aplicações de pesquisa, sendo $p=0,96$ no mês de nov/15, $p=0,36$ em jan/16 e $\mathrm{p}=0,193 \mathrm{em}$ mar/16. Assim, não estabelecendo padrão estatístico, o bairro de maior número de casos registrados percentualmente por região foi Barbados (ver Tabela 3).

Tabela 3 - Correlação incidência de casos de diarreia com bairros de Colatina

\begin{tabular}{cccccccc} 
& \multicolumn{2}{c}{ nov/15 } & \multicolumn{2}{c}{ jan/16 } & \multicolumn{2}{c}{ mar/16 } \\
\hline Bairros & Casos de diarreia & \% regional & Casos de diarreia & \% regional & Casos de diarreia & \% regional \\
\hline Colúmbia + Honório Fraga & 1 & 8,33 & 2 & 16,67 & 5 & 41,67 \\
\hline Lacê + São Brás + Martinelli & 4 & 9,3 & 9 & 20,93 & 12 & 27,91 \\
\hline Maria das Graças + Mario Giurizatto & 4 & 10,53 & 5 & 21,74 & 4 & 17,39 \\
\hline Barbados & 2 & 10,53 & 8 & 40 & 9 & 45 \\
\hline
\end{tabular}

No que tange à apresentação dos sintomas prodrômicos em outros moradores da mesma residência, constatou-se no questionário 1 que $11,58 \%$ dos entrevistados relataram a presença do sintoma em outro residente e 88,42\% responderam "Não". Quanto à febre, 12,5\% afirmaram ter outro morador com o quadro, e $86,46 \%$, negaram o ocorrido.

No questionário 2, 20,83\% dos interrogados afirmaram ter outro morador em sua residência com diarreia e 79,17\% negaram. A respeito da febre, $8,33 \%$ confirmaram e $91,67 \%$ disseram "Não". Durante a terceira entrevista, 26,04\% dos questionados afirmou ter diarreia em algum outro morador do mesmo domicílio, e, 73,96\%, não. Referente à febre, 14,58\% dos consultados garantiu que outro morador do mesmo domicílio apresentou o quadro e $85,42 \%$, não. 
Figura 2 - Incidência de diarreia e febre em outro morador da mesma residência do entrevistado

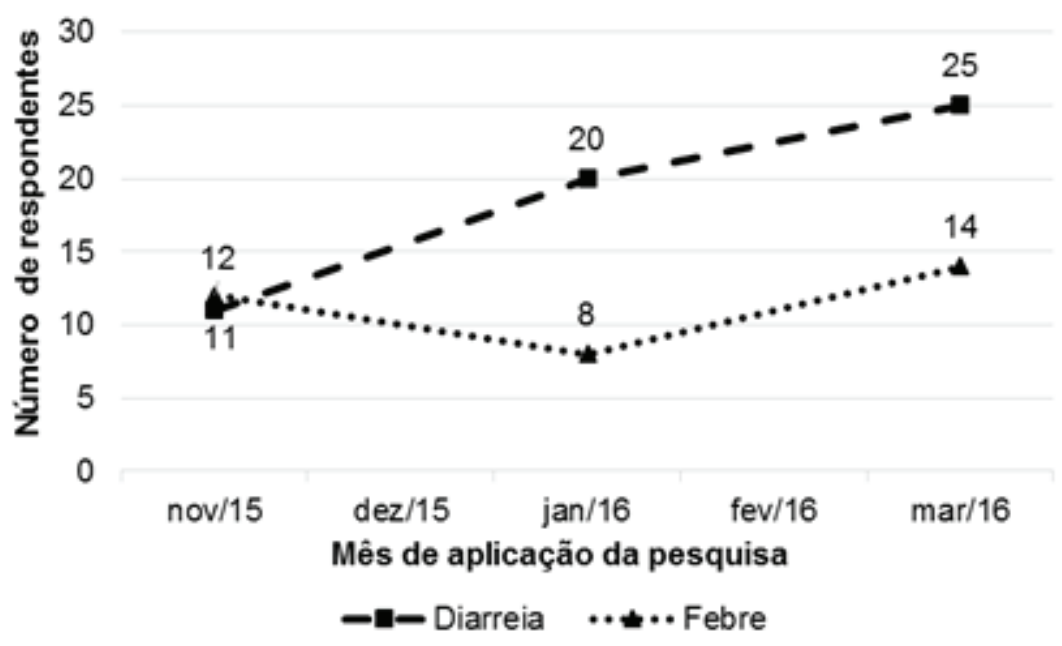

Encontrou-se uma correlação estatística, por meio do teste qui-quadrado (valor $p=0,040$ ), na ocorrência de diarreia associada ao modo de armazenamento da água declarado durante a aplicação dos questionários. Os achados evidenciam que houve maior incidência de alterações intestinais na população que armazenou água em caixas d'água (em números absolutos, 7 de 13 pessoas). Já nas demais opções foram demonstradas taxas percentuais de "não ocorrência de diarreia" maiores.

Analisou-se, também, a relação entre a procedência da água de consumo com a incidência de máculas, eritemas, prurido e demais afecções de pele nos seis meses seguintes à chegada dos rejeitos de minério, no entanto, não houve relação estatística entre os parâmetros avaliados, pois a aplicação do teste $\mathrm{G}$ resultou no valor $\mathrm{p}=0,082$.

Outro dado observado foi o aumento no relato de afecções de pele entre o questionário 2 e o questionário 3 (34,7\% no Q2 para 47,4\% no Q3), todavia este fenômeno não possui valor estatístico sob julgamento do teste qui-quadrado.

Ainda em relação à procedência da água para consumo, encontrou-se variações entre as coletas dos questionários aplicados, tais como o aumento do consumo da água proveniente de poços artesianos, redução no percentual de usuários da empresa distribuidora e aumento no consumo de água mineral, conforme o demonstrado na Figura 3.

Figura 3 - Achados na variação da procedência da água para consumo

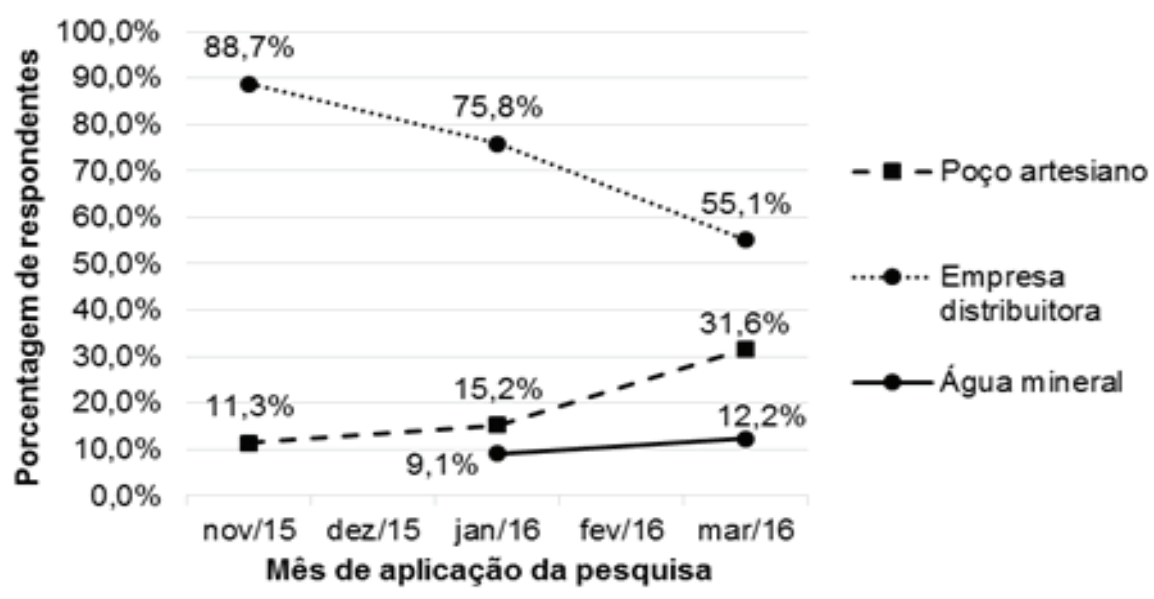




\section{$41 / /$}

Esses achados, na variação da procedência da água de consumo, inferem a abdicação de 33,6\% da população sobre a utilização de água distribuída por empresas de abastecimento, em outras palavras, houve redução do consumo da água coletada diretamente do rio Doce. Em contrapartida, houve aumento na utilização de coleções hídricas como os poços artesianos (com crescimento total de 20,3\%, entre os meses de novembro/2015 a março/2016), e consumo aumentado de água mineral envasada. Porém, quanto aos dados anteriores, não foram aplicados testes probabilísticos que comprovassem a relevância estatística dos achados.

\section{DISCUSSÃO}

Com a aplicação dos questionários, foi observado que a maior parte das pessoas entrevistadas não confiavam nos dados sobre a água apresentados pelos órgãos e instituições responsáveis pelo seu controle de qualidade (média de $86,73 \%$ dos entrevistados).

Vale salientar que, mesmo antes da aplicação da pesquisa em campo, já se esperava certa desconfiança por parte da população em relação a essas informações devido à grande repercussão do desastre ambiental ocorrido nas mediações da represa ainda em Minas Gerais, e os possíveis danos à saúde que tal situação poderia causar para as populações das cidades atingidas pela lama, como Colatina. Esta, que é a segunda cidade banhada pelo Rio Doce no Espírito Santo, o temor de danos à saúde decorrentes do consumo da água captada no manancial faz grande parte da população não beber e não cozinhar com o produto que chega às suas torneiras, ocasionando acréscimo no consumo de água proveniente de fontes minerais e revelando uma das inconveniências vividas por essas pessoas, como os gastos adicionais às despesas domésticas.

Os resultados dos questionários mostram que parte dos entrevistados (10,10\%) utilizava a água diretamente do Rio Doce antes da passagem dos rejeitos. Após a chegada da água contaminada pelo acidente ambiental, houve receio por parte da população em consumir o recurso. Entretanto, após a aplicação do questionário 3, percebe-se que este receio decaiu e que houve retorno do uso da água em taxas até maiores (14,29\%) que as do primeiro questionário identificado na Figura 3, isso após os esclarecimentos efetuados pelos pesquisadores aos entrevistadores a respeito de cuidados para lidar com a situação.

Foi avaliada a incidência de diarreia na população ribeirinha de Colatina tendo em vista a grande importância epidemiológica e social da sintomatologia prodrômica e suas consequências, tais quais desidratação e a internações, principalmente de crianças e idosos, ocasionando gastos com a saúde e perda de dia de trabalho pela população economicamente ativa.

Observou-se um aumento crescente de ocorrência de diarreia desde o primeiro questionário no dia 9 de novembro de 2015, aplicado antes dos rejeitos de minério chegarem em Colatina, até 
o último no mês de março de 2016. Apontando assim, uma possível relação entre esse desastre ambiental e o quadro clínico encontrado. Vale ainda destacar que devido à falta de água ou o medo de usar água inviável para o consumo, a população realizou o armazenamento de água em baldes e caixas d'água, por exemplo, o que possivelmente, pelo manejo hídrico inadequado, contribuiu para esse quadro.

A Tabela 3, mostra a localidade de Barbados com o maior número de casos de diarreia registrados percentualmente por região, indicando assim, uma ampla discussão de possíveis variáveis que propriciem essa maior ocorrência. É valido evocar, que essa localidade é geograficamente passível de maior acúmulo de sedimentos no leito do rio, uma vez, que observa-se curvatura aguda da margem fluvial.

A partir da análise dos questionários e da Figura 2 foi possível constatar um aumento considerável e contínuo no número de moradores que coabitam com os entrevistados que apresentaram sintomas de diarreia no decorrer da passagem da lama de dejetos pela cidade. Embora devidamente orientados sobre os riscos, alguns moradores afetados continuaram a consumir a água proveniente do rio contaminado, o que pode estar intimamente relacionado com a crescente incidência de diarreia, juntamente com o armazenamento impróprio de água potável nas residências, visto que organismos patogênicos se beneficiam e proliferam em reservatórios nessas condições.

Em relação ao quadro de febre, houve decréscimo, 4 casos, no número de casos de coabitantes após a passagem da água contaminada e no intervalo entre a primeira e a segunda aplicação de questionários. Entre a segunda e a terceira aplicação, percebe-se aumento, 6 casos.

Dentre as análises efetuadas com relevância estatística, a relação entre a forma de armazenamento e a ocorrência de quadros de diarreia demonstra um possível erro de estocagem ou contaminação por vias de abastecimento de água (provinda do rio Doce), com consequências para a saúde. As maiores taxas de diarreia associam-se à estocagem em caixas d'água, meio em que o volume de água acumulada é maior, permanecendo, portanto, mais tempo retida, servindo como ambiente favorável à cultura de micro-organismos.

Independente das ações de educação empregadas, as queixas de alteração intestinal cresceram na comparação dos questionários 1, 2 e 3, o que demonstra a necessidade de abordagens diferenciadas para a educação e conscientização dos cuidados corretos e manejo da água.

Sabendo-se por meios extraoficiais e não-científicos que os rejeitos de minério vindos de Mariana-MG continham metais pesados e outras substancias tóxicas, atentou-se no presente trabalho para as afecções de pele como irritação, manchas, queda de cabelo, prurido e irritabilidade, sendo que metais como, o mercúrio, cromo, prata e alumínio podem causar irritação na pele, as quais 
são identificadas por Ferreira e Wermelinger ${ }^{10}$ (2013). Dessa forma, analisando os questionários realizados em 2016 foi detectado que considerável parcela da população entrevistada apresentava alguma afecção de pele $(34,69 \%)$.

Vale destacar que foram observadas queixas, por parte dos entrevistados, quanto ao incômodo que as alterações na pele lhes causaram, além do constrangimento relatado por uma das entrevistadas, segundo a qual outras pessoas que a visitaram apresentaram manchas e prurido na pele.

Ressaltamos, ainda, a importância dos resultados que demonstram elevada incidência de sintomas prodrômicos, que sugerem a necessidade de uma intervenção para maior controle de qualidade da água, de modo a evitar, não só o desconforto das pessoas, mas também uma economia pública em relação aos gastos médicos.

Nesta pesquisa, também foi possível observar que grande parte das pessoas entrevistadas não vislumbram uma possível melhora da atual condição do rio Doce $(69,73 \%$ ), além de que a grande maioria (44,39\%), também relatou que essa ocorrência dificultou muito sua vida em relação as atividades diárias, lazer, entre outras. A desconfiança dos moradores ainda é frequente e soma-se a uma sombria, ou nenhuma, perspectiva de melhoras. Isso, é evidenciado pelos dados da Figura 3, onde há uma iniciativa dos ribeirinhos em recorrer a poços artesianos como alternativa de busca de água de melhor qualidade.

A partir de uma nova perspectiva obtida através dos resultados, há uma real necessidade de redefinir temáticas de educação em saúde por parte dos órgãos governamentais e institucionais, visto a carência de técnicas de abordagens informativas de maior eficácia e regularidade no cotidiano das comunidades, no que tange a saúde pública e coletiva. Os valores crescentes das sintomatologias (febre, diarreia e afecções de pele) equivalem a uma tradução para efeitos negativos nos âmbitos da saúde biopsicossocial e econômicos, relevantes na pesquisa, em um momento racional de análise das consequências do desastre ambiental causado pelo homem.

Alguns problemas não podem ser identificados a curto prazo, sendo necessário estudos continuados por um período de tempo maior, visando melhores análises da qualidade da água e demais danos à saúde humana. Ademais, faz-se importante a inserção da população não ribeirinha em próximas pesquisas, visto que a distribuição de água proveniente do Rio Doce abrange todo município de Colatina.

\section{REFERÊNCIAS BIBLIOGRÁFICAS}

1. Calijuri MC, Cunha DGF. Engenharia ambiental, conceitos tecnologia e gestão. São Paulo; Elsevier; 2013. 
2. Freitas CM, Silva DRX, Sena ARM, Silva EL, Sales LBF, Carvalho ML, Mazoto ML, Barcellos C, Costa AM, Oliveira MLC, Corvalán C. Desastres naturais e saúde: uma análise da situação do Brasil. Rev Ciência \& Saúde Coletiva. 2014. 19(9):3645-3656.

3. Castro ALC. Manual de planejamento em defesa civil. Ministério da Integração Nacional/ Departamento de Defesa Civil. 1. ed. Brasília; 1999, p. 133.

4. Mahan KL, Escott-Stump S. Alimentos, Nutrição \& Dietoterapia. 11. ed. Roca; São Paulo; 2005; 1242p.

5. ANA - Agência Nacional das Águas. Bacia Hidrográfica do Rio Doce (2015). Disponível em: http://www.caminhoaguas.org.br/bacias/Doce_usos.html.

6. Malagutti W. Efeitos das Catástrofes e/ou Desastres Naturais na Saúde Pública. 2012. Disponível em: http://posugf.com.br/noticias/todas/1277-efeitos-das-catastrofes-e-ou-desastresnaturais-na-saude-publica-por-william-malagutti.

7. Philippi-Jr A. Saneamento, Saúde e Ambiente: Fundamentos para um desenvolvimento sustentável. 1. ed. São Paulo: Manole; 2008. v.2, 842 p.

8. CBH-DOCE - Comitê da Bacia Hidrográfica do Rio Doce Cartilha Sobrevivência em Colapso de Abastecimento de Água. 2015. Disponível em: http://www.cbhdoce.org.br/ informacoesrompimentodasbarragens/cartilha-sobrevivencia-em-colapso-de-abastecimento-deagua/.

9. COVISA - Coordenação de Vigilância em Saúde. Orientações à população para uso da Água. São Paulo: Prefeitura do Município de São Paulo; 2015. 6 p. Disponível em: http://www. prefeitura.sp.gov.br/cidade/secretarias/upload/chamadas/informe_uso_seguro_da_agua_alteraes_ agosto_1439308548.pdf.

10. Ferreira AP, Wermelinger ED. Concentrações séricas de metais e suas implicações para a saúde pública. J Health Sci Inst. 2013. 31(1): 13-9.

11. Athas F. Risco de doenças após acidente em barragens preocupa especialistas. Jornal do Oeste. (2015). http://www.jornaldooeste. com.br/cotidiano/2015/11/risco-de-doencas-aposacidente-em-barragens-preocupa-especialistas/1499690/.

12. IBAMA - Instituto Brasileiro do Meio Ambiente e dos Recursos Naturais Renováveis Laudo técnico preliminar: impactos ambientais decorrentes do desastre envolvendo o 
rompimento da barragem de Fundão, em Maria, Minas Gerais. 2015. Disponível em: http://www. ibama.gov.br/phocadownload/noticias_ambientais/laudo_tecnico_preliminar.pdf.

13. Portal r7.com. Relatório analítico parcial. 2015. Disponível em: http://www.r7.com/r7/ media/pdf/relatorio-lama.pdf.

14. Vieira, S. Introdução a Bioestatística. 4. ed. São Paulo: Elsevier Editora Ltda; 2008. 348p.

15. Callegari-Jaques SM. Bioestatística: Princípios e Aplicações. Porto Alegre; Artmed SA; 2008.

Artigo apresentado em 19/08/16

Artigo aprovado em 24/10/16

Artigo publicado no sistema em 25/10/16 


\section{APÊNDICE A - QUESTIONÁRIO 1}

\section{1-Identificacão: Nome:}

Mapa: $\mathrm{n}^{\mathrm{o}} \quad$ Grupo de pesquisa:

Bairro:

Endereço:

Contato com ESF:

\section{2-Moradia}

2.1 Quantos moradores: ( )1 ( )2-4 ( )maior que 4 pessoas

22 Idade ( )12-25 anos ( )26-60 anos ( ) maior que 60 anos

2.3 Tem crianças na casa? ( ) Sim ( )Não

2.4 Tem idosos na casa? ( ) Sim ( )Não

2.5 Escolaridade: ( )Não-alfabetizado ( )Fundamental ( )Médio ( )Superior

2.6 Moradores com necessidades especiais: ( ) Sim ( )Não

2.7 Se sim, qual? ( )Locomoção ( ) Visual ( ) Auditiva ( ) Outras

2.8 Morador (es) há quanto tempo no local: ( ) $<1$ ano ( )entre 1 e 5 anos ( )maior que 5 anos

2.9 Tipo de Construção: ( )Alvenaria ( )Madeira ( )Barro ( )Outro

2.10 Destino dos dejetos sanitários: ( ) Rede esgoto municipal ( )Rio ( )Fossa

\section{3-Sobre a Água}

3.1 Procedência da água de consumo: ( )Poço artesiano ( )Empresa distribuidora ( ) direto ao Rio ( )Outro

3.2 Você vai armazenar água para consumo? ( ) Sim ( ) Não

3.3 Se sim, como você armazenará esta água? ( )Caixa d'água ( ) Baldes ( )Poço ( )Outro 3.4 Esta água da reserva é potável? ( ) Sim ( ) Não

3.5 Você sabe como deixar a água não potável em ideal para consumo? ( )Sim （ )Não 3.6 Você usa água coletada diretamente do Rio Doce para alguma atividade? ( )Sim ( ) Não 
3.7 Se sim, qual? ( )Para beber/preparo de refeição ( )Banho ( )Irrigação ( )Pesca ( )Uso animal

\section{$\underline{\text { 4-Sobre Orientações gerais }}$}

4.1 Você Recebeu orientação de alguma fonte? ( ) Defesa civil ( )Bombeiros ( )Associação de Moradores ( )Jornal ( )TV ( ) não recebeu informação

4.2 Qual orientação você recebeu? ( )Consumo/racionamento de água ( )Identificação de riscos à saúde ( )Desocupação de áreas

\section{5-Sobre sua Saúde: Nos últimos 3 meses...}

5.1 Esteve em alguma consulta médica? ( ) Sim ( )Não

5.2 Se sim, qual? ( ) Consulta de rotina ( ) Doenças parasitárias ( ) Doenças infecciosas ( ) Outros

5.3 Teve quadro de diarreia? ( ) Sim ( )Não

Se sim, especifique.

5.4 Tempo da intercorrência ( ) 1 dia ( ) 1-3 dias ( ) maior que 3 dias

5.5 Frequência em 3 meses ( ) até uma vez ( ) 2-4 vezes ( ) mais que 4 vezes

5.6 Teve quadro de febre? ( ) Sim ( )Não

Se sim, especifique.

5.7 Tempo da intercorrência ( ) 1 dia ( ) 1-3 dias ( ) maior que 3 dias

5.8 Frequência em 3 meses ( ) até uma vez ( ) 2-4 vezes ( ) mais que 4 vezes

5.9 Alguma outra pessoa da residência teve quadro de diarreia nos últimos três meses?

( ) Sim ( )não.

5.10 Alguma outra pessoa da residência teve quadro de febre nos últimos três meses?

( )Sim ( )não.

5.11 Atualmente alguma pessoa da residência está com algum quadro infeccioso?

( ) $\operatorname{Sim}$ ( ) Não 


\section{APÊNDICE B - QUESTIONÁRIOS 2 e 3}

\section{1-Identificacão: Nome:}

Mapa: $n^{\circ}$

Grupo de pesquisa:

Bairro:

Endereço:

Contato com ESF:

\section{2-Sobre a Água}

2.1 Você tem armazenado água para consumo? ( ) Sim （ ) Não

2.2 Se sim, como você tem armazenado esta água? ( )Caixa d'água ( )Baldes ( )Poço ( ) Outro

2.3 Procedência da água de consumo nos últimos 60 dias:

( ) Poço artesiano ( ) Empresa distribuidora ( ) direto ao Rio ( ) Água previamente armazenada

2.4 Esta água da reserva é potável? ( ) Sim （ ） Não

2.5 Você sabe como deixar a água não potável em ideal para consumo? ( ) Sim （ ) Não

2.6 Esta água da reserva é a única fonte para seu consumo? ( ) Sim （ ) Não

2.7 Você usa água coletada diretamente do Rio Doce para alguma atividade? ( ) Sim ( ) Não

2.8 Se sim, qual? ( )Para beber/preparo de refeição ( )Banho ( )Irrigação ( )Pesca ( ) Uso animal

\section{3-Sobre Orientacões gerais: nos últimos 60 dias}

3.1 Você Recebeu orientação de alguma fonte? ( ) Defesa civil/Bombeiros ( ) Associação de Moradores ( ) Acadêmicos Unesc （）Jornal/TV/Rádio/Internet

( ) não recebeu informação 3.2 Qual orientação você recebeu? ( )Consumo/ racionamento de água ( )Identificação de riscos à saúde ( )Desocupação de áreas

\section{4- Sobre a Saúde: nos últimos 60 dias}

4.1 Esteve em alguma consulta médica? ( ) Sim ( )Não

4.2 Se sim, qual? ( ) Consulta de rotina ( ) Doenças parasitárias ( )Doenças infecciosas ( ) Outros 4.3 Teve quadro de diarreia? ( ) Sim ( ) Não

Se sim, especifique.

4.4 Tempo da intercorrência ( ) 1 dia ( ) 1-3 dias ( ) maior que 3 dias 
4.5 Alguma outra pessoa da residência teve quadro de diarreia nos últimos 60 dias? ( )Sim ( ) Não.

4.6 Teve quadro de febre? ( ) Sim ( ) Não

Se sim, especifique.

4.7 Tempo da intercorrência ( ) 1 dia ( ) 1-3 dias ( ) maior que 3 dias

4.8 Alguma outra pessoa da residência teve quadro de febre nos últimos 60 dias? ( ) Sim ( ) Não

4.9 Atualmente alguma pessoa da residência está com algum quadro infeccioso?( )Sim ( )Não

4.10 Há grávida(s) na casa? ( )Sim ( )Não

Se sim, especifique.

4.11 Tempo de gestação ( ) Primeiro trimestre ( ) Segundo trimestre ( ) Terceiro trimestre 4.12 Ainda se sim, em relação a gravidez. Houve pelo menos três destas intercorrências: febre, dores musculares e/ou articulares, dor de cabeça, náuseas, vômitos. ( ) Sim ( )Não

4.13 Apresentou alguma afecção de pele (coceira, infecção, queda cabelo, etc.)? ( )Sim ( ) Não

5- Você vê alguma perspectiva de melhora da atual condição do rio Doce? ( )Sim （ )Não

6- O quanto essa ocorrência dificultou sua vida (atividades diárias, lazer, etc.)?

( ) Nada ( ) Pouco ( ) Muito ( ) Totalmente

7- Você confia nos dados apresentados sobre a água pelos órgãos e instituições responsáveis pelo controle de qualidade? ( )Sim ( )Não

8- Qual a avaliação que você faria sobre as medidas adotadas pelos acadêmicos em medicina do UNESC para diminuir as consequências e agravamentos da situação?

( ) Ótimo ( ) Bom ( ) Regular ( ) Ruim ( ) Péssimo 